\title{
The Tactics of Safe Removal of Heart Myxomas; The Experience of 796 Operations
}

\author{
Rostyslav Vitovskiy ${ }^{1}$, Volodymyr Isaienko ${ }^{1}$, Olexandr Pishchurin ${ }^{1}$, Volodymyr Onishchenko ${ }^{1}$, \\ Igor Martyshchenko ${ }^{1}$, Dmitriy Dyadyun ${ }^{1}$
}

${ }^{1)}$ N.M. Amosov National Institute of Cardio-Vascular surgery of the Academy of Medical Sciences of Ukraine, Kyiv, Ukraine.

\begin{abstract}
Objective: In the structure of cardiac new formation, myxoma constitute $80-90 \%$ of benign heart tumors. The aim of the study was to determine the features of diagnosis and to search the tactics of optimal and the safe surgical treatment of myxoma of the heart.
\end{abstract}

Material and methods: In N.M. Amosov Institute of Cardio-Vascular surgery of the Academy of Medical Sciences of Ukraine for period from 1.01.1969 to 1.01.2017 889 patients with primary heart tumors had surgical treatment. The myxomas of heart (MH) was founded in $796(89,5 \%)$ cases, from them in $696(87,4 \%)$ cases - MH of left atrium (LA). The other benign heart tumours were observed in $33(3,7 \%)$ cases, malignant heart tumours - in $60(6,8 \%)$ cases.

Results: Hospital mortality in the surgical treatment of MH was $4.9 \%$ (39 cases).

Conclusions: Over the past 16 years, 433 operations have been performed without lethal results, due to the peculiarities of the tactics of emergency diagnosis and surgical treatment, and radicality of removal of heart tumors.

Keywords: Myxoma, benign heart tumors, surgical treatment. 


\section{Introduction}

The primary tumours of heart (PTH) show up a various clinical picture, imitating other diseases of heart. In a structure cardiac tumours myxomas make $80-90 \%$ of benign tumours of heart. Frequency of diagnostics of primary heart tumors (from which more than $80 \%$ are morphologically of benign tumours) in relation to the acquired heart diseases makes from $1,5 \%$ to $2 \%$, or from $0,09 \%$ to $1,9 \%$ from the incurrence of the hospitalized patients. ${ }^{(1,2)}$ Clinical displays come to light mainly in the late stages of disease, in addition, a prognosis at this pathology remains unfavorable. ${ }^{(1,2)}$ Questions of diagnostics of new formations of heart and their adequate, quite often urgent surgical treatment are actual. ${ }^{(3,5)}$

Purpose of the research - to determine the peculiarities of diagnostics and to search the tactics of optimal and the safe surgical treatment of myxoma of the heart.

\section{Material and methods}

In N.M. Amosov Institute of Cardio-Vascular surgery of the Academy of Medical Sciences of Ukraine for period from 1.01.1969 to 1.01.2017889 patients with the verified primary tumours of heart. Nonmyxomas benign tumours of heart (NBTH) were observed in $33(3,7 \%)$ case, malignant tumours - in 60 (6.8\%). Rabdomiomas were observed in $9(27,3 \%)$ cases, $5(15,2 \%)$ - hemangiomas, in $8(24,2 \%)$ - papillarus fibroelastomas, for $3(9,1 \%)$ cases were lipomas, fibromas, and lejomiofibromas; and for $1(3,0 \%)$ cases were exposed fibroma and immature teratoma. Age of patients formed from 1 day to 67 years (on the average 34,5 $\pm 4,3$ years).

The myxomas of heart $(\mathrm{MH})$ are exposed at 796 $(89,6 \%)$ patients, from them in $696(87,4 \%)$ cases $-\mathrm{MH}$ the left atrium (LA). The myxomas of right atrium (RA) were determined in $73(9,2 \%)$ supervisions, $\mathrm{MH}$ in the left (LV) and in the right (RV) ventricles - for $8(1,1 \%)$ cases accordingly. Multicentral growth of tumour with a defeat two or three chambers of heart was discovered at $11(1,4 \%)$ patients. Age of patients with $\mathrm{MH}$ made from 3 to 78 years (on the average 47,5 $\pm 3,4$ years), from them $577(72,5 \%)$ in age from 31 to 60 years.

\section{Results and discussion}

At the analysis of supervisions the increase of frequency of registration of patients is exposed with $\mathrm{MH}$ in In N.M. Amosov Institute of Cardio-Vascular surgery: for period from 1969 to 1990 amount of patients with MH made $160(20,1 \%)$ cases, and for period from 1991 to 2017 are $636(79,9 \%)$ cases, that is conditioned by both wide introduction in diagnostics of ultrasonic research of heart and probable increase of frequency of this disease.

The leading clinical display of disease was stagnant cardiac insufficiency, that was conditioned by partial damming by the tumour of the valvular openings with subsequent development of violation of hemodynamics in the proper chambers of heart, which was determined for $736(92,5 \%)$ patients with MH. By III and to the IV functional classes of NYHA classification were taken $289(36,3 \%)$ and $68(8,5 \%)$ patients accordingly, that in these groups frequently required urgent surgical treatment. Diameter of foundation MH made from 0,5 to 7,5 sm. Thus in $688(86,4 \%)$ cases by the prevailing area of fixing $\mathrm{MH}$ there was a interatrium septum (IAS).

The losses of consciousness and the attacks of dizzinesses which was determined at $172(21,6 \%)$ patients were the important clinical symptoms of MH. For 112 $(14,1 \%)$ patients appearance of these symptoms was related to certain position of body, that appeared characteristic for atrium localizations of tumours and not observed in the cases of ventricles localization $\mathrm{MH}$.

Such a heavy complication of clinical flow of this disease, as an embolic syndrome was determined for patients with $\mathrm{MH}$ in $43(5,4 \%)$ cases, thus on a background a sine rhythm. From these patients embolism of cerebrum vessels was took place in $34(4,3 \%)$ cases from which in $9(1,1 \%)$ - repeatedly. At $9(1,1 \%)$ patients embolism of vessels of other organs was registered - kidney, vessels of lower and overhead extremities.

Pains in area of heart were registered at 298 (37,4\%) patients with various localizations $\mathrm{MH}$. More frequent than all pains showed up as sense of weight in a thorax and did not carry anginal character. In $696(84,6 \%)$ cases duration of symptoms of disease did not exceed 1 year to the operation. Displays of insufficiency of circulation of blood at $\mathrm{MH}$ (shortness of breath, palpitation, dizziness, losses of consciousness) were to different expressed depending on position of body of patient in 216 $(27,1 \%)$ supervisions. 
At auscultation for patients with MH noises, similar with such at rheumatic heart diseases, came to light. Changeability of ?uscultations displays at a stably sine rhythm in course of time and at the change of position of body of patient was determining, that is conditioned by displacement of tumour in relation to the valves of heart and marked for $153(19,2 \%)$ patients. Different violations of rhythm, as clinical displays $\mathrm{MH}$, came to light for $237(29,8 \%)$ patients. It is necessary to notice that at $178(22,4 \%)$ patients they showed up proof are $111(13,9 \%)$ cases, or parocsismal were at $67(8,5 \%)$ cases tachycardias in combination with extrasystole.

Such clinical displays $\mathrm{MH}$, as a general weakness, rapid fatigueability and indisposition - at $499(62,7 \%)$ patients, middle increase temperature - in 449 (56,4\%) cases; pains in the articulations and muscles - at 248 $(31,2 \%)$, decline of mass of body - for 309 (38,8\%) patients were considered, as a general reaction of organism on a tumour.

A basic diagnostic method in the complex of diagnostics of primary tumours of heart (PTH) is EkhoCG. From 796 patients with MH in 753 (94,6\%) cases, since 1984, it was produced EkhoCG. Among these patients in $512(68,2 \%)$ cases a tumour localized as heterogeneous on the structure by volume formation of cellular character with diffuse uneven contours which changed in the process of motion. In other $239(31,8 \%)$ cases by volume new formation of homogeneous character was visualized with clear even edges. In 57 (7,6\%) cases disseminations of calcium were determined as bright echo-signals of various localization. Foundation $\mathrm{MH}$ came to light for $612(81,5 \%)$ patients from which in $389(63,5 \%)$ cases location of attachment of tumour was determined the on the area of IAS.

Expressed clinical displays, related to damming of the valvular openings at preparation to the operation took place at $46(5,8 \%)$ patients with $\mathrm{MH}$, namely during transporting and piling of patients on an operating table. In such cases it was acknowledged by expedient to give to the patients halfsitting position with a turn on a right side at the beginning of surgical interference.

All operations, except for 15 (1,9\%), which was executed on the early stage of surgery $\mathrm{MH}$ and 1 case of right ministernotomy in 2015, conducted access from middle sternotomy, that provided optimum conditions for the delete of tumours of any localization.

At a delete MH LA was used different surgical accesses which differed frequency of fragmentations of new formations at their delete. Application of LA access in $122(15,3 \%)$ cases MH LA was accompanied by fragmentation $\mathrm{MH}$ for $47(38,1 \%)$ patients. Traditional access appeared most comfortable to MH LA through RA and IAS, diminishing of frequency of fragmentation of tumour was here registered to $21,1 \%$ (109 patients on 521 operations). For $8(1,0 \%)$ patients with the myxomas of LA we were forced to apply the combined access of right atriotomy and septotomy with left atriotomy, that allowed safely to make off an operation. In $48(6,1 \%)$ cases, at the exposure of large (to $8-12 \mathrm{sm}$ ) myxomas of LA was used access from both atriums which allowed practically fully to avoid fragmentation of tumour.

At macroscopic research $\mathrm{MH}$ it was certain that tumours it was been: villiferous - in $459(57,7 \%)$ cases and compact new formations of ovoid or rounded form, with a brilliant smooth, sometimes hilly surface - in 337 (42,3\%) accordingly.

Pathology of valves, wich accompany at $\mathrm{MH}$, determined at $57(6,9 \%)$ patient. There was the isolated defeat of mitral valve (MV) in $36(4,5 \%)$ cases, in $18(2,3 \%)$ - tricuspid valve (TV), for 1 case $(0,1 \%)$ is the accompany defeat mitral and aortic, and the isolated defeat of aortic valves (AV). Among them the mechanical damage of valvular structures found out a myxoma at $23(2,9 \%)$ patients. Other pathology of valvular apparatus showed up relative insufficiency of valve due to the expressed expansion of fibrotic ring: tricuspid - in $17(2,1 \%)$ and mitral - in $13(1,6 \%)$ cases accordingly.

Engaging of valvular apparatus in a tumour process was observed at $8(1,0 \%)$ patients. Thus for a $1(0,1 \%)$ patient the myxoma of RV attached to the papillars muscles and chords of TV, and in $7(0,9 \%)$ cases of myxoma of LA struck the front leaflet of MV. The surgical correction of valvular defeats was executed at $54(6,8 \%)$ patients: in $12(1,5 \%)$ cases is replacement of valves $(9$ - MV, 1 - TV, 1 - AV, 1 - AV + MV), in 43 (5,4\%) are repair operations with a positive functional effect.

At surgical treatment $\mathrm{MH}$ hospital mortality was 
$5 \%$ (39 cases). In the last 16 years 433 operations were executed without fatal outcomes. Reasons of fatal outcomes it was been: neurological complications - at 16 $(46,2 \%)$ patients; material embolism - in $7(17,9 \%)$ cases, infarct of myocardium - in $3(7,7 \%)$ cases; septic complications - in $1(2,6 \%)$ case; errors of operations - in $5(12,9 \%)$ cases.

In a follow-up period the results of surgical treatment $\mathrm{MH}$ were studied for 679 patients $(89,8 \%$ written) in terms from 6 months to 46 years (on the average $19,5 \pm 4,2$ years). Survivability in terms to 20 years was $79,8 \%$. In a follow-up period in I functional classes of NYHA classification were $532(78,4 \%)$ patients, in II functional classes of NYHA - 101 (14,8\%). Relapses MH discovered for $16(2,1 \%)$ patients in period from 2 to 12 years (on the average $3,5 \pm 0,4$ years) after a primary operation. Thus in 4 cases of relapse MH (25\%) the myxomas syndrome took place.
At surgical treatment of NBTH hospital mortality was $3,0 \%$ ( 1 case). 2 patients died in a follow-up period, the relapse of disease in the first years after an operation was not exposed.

\section{Conclusions}

1. In the last 16 years 433 operations were executed on an occasion $\mathrm{MH}$ without fatal outcomes, that is conditioned by optimum tactic of diagnostics and urgency of surgical treatment, which reduce frequency of the preoperated complications and provide safety and radicalism of delete of tumours of heart.

2. The adopted tactics ensure the effectiveness of surgical treatment $\mathrm{MH}$, confirmed by given follow-up results: in I functional classes of NYHA classification were $532(78,4 \%)$ patients, in II functional classes of NYHA - 101 (14,6\%) patients accordingly; survivability in terms to 20 years was $79,8 \%$.

\section{References}

1. M. S. Anvari, M. Naderan et al. // Clinicopathologic Review of NonMyxoma Cardiac Tumors: A 10-Year Single-Center Experience. - Cardiology. - 2014. - Vol. 129 - P. 199-202

2. Витовский Р.М., Захарова В.П. и др.// Случай рецидива миксомы левого предсердия. - Щорічник наукових праць Асоціації серцевосудинних хірургів України. - 2014.- № 22. - Р. 20-24.

3. Diaz, C. Di Salvo et al. // Left atrial and right ventricular myxoma: an uncommon presentation of a rare tumour. - Interact. Cardiovasc. Thorac. Surg. - 2011. - Vol. 12, ? 4. - P. 622-623.
4. Hoffmeier A, Sindermann JR, Scheld HH et al. // Cardiac tumors-diagnosis and surgical treatment. - Deutsches Ärzteblatt International. - 2014. - Vol. 111(12) - P. 205-11.

5. Habertheuer A, Laufer G, Wiedemann D. et al. Primary cardiac tumors on the verge of oblivion: a European experience over 15 years. J Cardiothorac Surg. 2015; 10 - P. 56-60.

6. Isogai $\mathrm{T}$, Yasunaga $\mathrm{H}$, Matsui $\mathrm{H}$. et al. Factors affecting in-hospital mortality and likelihood of undergoing surgical resection in patients with primary cardiac tumors. J Cardiol. 2016, 10 - P. 1016

Received: 24/04/2018

Accepted: 28/05/2018

Published: 05/062018

Disclosure and conflicts of interest:

The authors declare no conflict of interest.

Corresponding author:

Volodymyr Isaienko

Mail:vladvis6@gmail.com 